\title{
SINTESIS SURFAKTAN TURUNAN AMIDA YANG DIPEROLEH DARI REKASI METIL RISINOLEAT DAN ETILENDIAMINA
}

\author{
${ }^{1}$ Daniel, ${ }^{2}$ Agustina Rahayu Magdaleni, ${ }^{3}$ Soerja Koesnarpadi \\ 1,3 Jurusan Kimia FMIPA Universitas Mulawarman, Indonesia \\ ${ }^{2}$ Laboratorium Fisiologi Fakultas Kedokteran Universitas Mulawarman, Indonesia \\ *corresponding Author : daniel_trg08@yahoo.com
}

\begin{abstract}
Interesterification of castor oil with methanol using base catalyst gave mixture of fatty acid methyl esther (FAME) castor oil. Methyl risinoleate as major composition of methyl esther castor oil was subjected to column chromatography using petroleum ether:diethyl ether $(19: 1, \mathrm{v} / \mathrm{v})$ as eluent, to give yield $73 \%$. Amidation of methyl risinoleate with ethylendiamine under refluks condition using benzene as solvent for \pm 12 hours and catalyst $\mathrm{NaOCH}_{3}$, gave 1,3-Dirisinoleil-Etilendiamida compound and 59\% yield. The reactioned product 1,3-Dirisinoleil-Etilendiamida has been confirmed its structure using FT-IR spectroscopy, and Hidrofile Lipofile Balance (HLB) value was determined by titration method 12,56.
\end{abstract}

Keywords: Interesterification, Amidation, Castor Oil, Amide.

\section{PENDAHULUAN}

Asam risinoleat merupakan komposisi utama dalam minyak jarak (Ricinus communis L) yang merupakan turunan asam oleat yang memiliki gugus hidroksil pada posisi $\omega-7$ dan ikatan $\pi$ pada posisi $\omega-9[1]$. Adanya gugus hidroksil tersebut memberikan suatu pemikiran untuk merubah senyawa ini keberbagai bentuk senyawa kimia lainnya yang diharapkan bermanfaat dalam bidang oleokimia. Senyawa 12-(Asetoksi) Metil Okta Deka-9-Enoat telah berhasil disintesis dari metil risinoleat yang dipisahkan dari minyak jarak dengan mengubah gugus hidroksilnya menjadi asetoksi [2].

Frykman telah mensintesis surfaktan turunan glukosa yakni 5-hidroksi amida asam lemak yang merupakan surfaktan yang bersifat biodegradable. Disamping itu juga telah banyak dikembangkan dan dipatenkan surfaktan polihidroksi amida asam lemak [3].

Kegunaan senyawa amida ini cukup luas baik dalam industri pertanian, farmasi, bahan makanan, minuman, kosmetik dan industri lainnya. Dalam industri farmasi khususnya dapat digunakan sebagai bahan obat-obatan.

Dalam penelitian ini, peneliti ingin mensintesis senyawa 1,3-DirisinoleilEtilendiamida yang memiliki gugus hidrofil $(\mathrm{OH})$ dari metil risinoleat dan gugus lifofil dari atom $\mathrm{C}$ rantai panjang pada metil risinoleat yang diharapkan dapat digunakan sebagai surfaktan[4].

Untuk mencapai tujuan tersebut, metil risinoleat merupakan komposisi utama metil ester asam lemak minyak jarak yang terdapat dalam bentuk metil ester asam lemak campuran direaksikan dengan etilendiamina kemudian dipisahkan dengan kromatografi kolom untuk memperoleh senyawa 1,3-DirisinoleilEtilendiamida. Yang menjadi permasalahan adalah Apakah metil risinoleat dapat dipisahkan dari metil ester asam lemak campuran minyak jarak dan selanjutnya apakah dapat dilakukan reaksi amidasi antara metil risinoelat dengan etilendiamina untuk membentuk senyawa 1,3Dirisinoleil-Etilendiamida. Tujuan Penelitian ini diharapkan senyawa metil risinolet dapat dipisahkan dari metil ester asam lemak campuran dari minyak jarak dan selanjutnya metil rissinoleat tersebut dapat diamidasi dengan etilendiamina membentuk senyawa 1,3Dirisinoleil-Etilendiamida yang dapat digunakan sebagai surfaktan.

\section{METODOLOGI PENELITIAN Bahan-bahan}

Bahan-bahan yang digunakan dalam penelitian ini adalah minyak jarak yang diperoleh secara ekstraksi dari biji jarak, n-heksana, benzena, petroleum eter, metanol, 2-propanol, $\mathrm{Na}_{2} \mathrm{SO}_{4}$ anhidrous, $\mathrm{KOH}, \mathrm{H}_{2} \mathrm{SO}_{4}(\mathrm{p})$, dietil eter, silika gel $60 \mathrm{G}$, Silika gel $40 \mathrm{H}$, etilendiamina, natrium metoksida, etil asetat dan iodium yang semuanya buatan E'Merck dan kertas saring whatman.

\section{Peralatan}


Alat-alat yang digunakan adalah labu leher tiga, pendingin bola, pengaduk magnet, batang pengaduk, termometer, timbangan magnet, beaker glass, erlenmeyer, statif dan klem, corong pisah, desikator, oven, kolom pengelusi, plat kromatografi lapis tipis, buret, alat destilasi vakum dan rotarievaporator. Penelitian ini dilakukan di Laboratorium Kimia Organik FMIPA USU dan analisis spektroskopi FT-IR dilakukan dilaboratorium Kimia Organik FMIPA UGM.

\section{Prosedur Penelitian \\ Isolasi Minyak Jarak}

Biji jarak dipisahkan dari cangkangnya selanjutnya dikeringkan dan dihaluskan. Serbuk biji jarak halus 500 gr dimaserasi menggunakan 2-propanol selama 48 jam. Ekstrak disaring dan filtrat ditambah $\mathrm{Na}_{2} \mathrm{SO}_{4}$ anhidrous, didiamkan selama 24 jam dan kemudian disaring, filtrat dirotarievaporasi untuk memperoleh minyak jarak.

\section{Pembuatan Metil Ester Asam Lemak Minyak Jarak}

Ke dalam botol aspirator dimasukkan sebanyak 2 gr $\mathrm{KOH}$ dan $100 \mathrm{ml}$ metanol. Kemudian dilakukan pengadukan menggunakan pengaduk mekanik dengan kecepatan 2000 rpm pada suhu kamar. Setelah semua $\mathrm{KOH}$ larut dalam metanol, dimasukkan 50 gr minyak jarak. Campuran diaduk dengan kecepatan 3000 rpm selama 1 jam. Kelebihan metanol diuapkan melalui rotarievaporator. Residu yang diperoleh dilarutkan dalam n-heksana dan dimasukkan dalam corong pisah. Lapisan atas diambil dan dicuci dengan akuades sebanyak 3 kali dan selanjutnya ditambah $\mathrm{Na}_{2} \mathrm{SO}_{4}$ anhidrous, disaring dan filtrat dirotarievaporasi untuk memperoleh metil ester asam lemak minyak jarak campuran. Untuk memperoleh metil risinoleat dari metil ester minyak jarak dilakukan pemisahan dengan kolom kromatografi menggunakan silika gel 40 $\mathrm{H}$ dengan eluent petroleum eter:dietyl eter (19:1, $\mathrm{v} / \mathrm{v}$ ) diperoleh metil risinoleat pada fraksi terakhir (fraksi 20-50).

\section{Pembuatan Senyawa 1,3-Dirisinoleil- Etilendiamida}

Metil risinoleat 62,4 gr $(0,2 \quad \mathrm{~mol})$ dilarutkan dalan benzena sebanyak $150 \mathrm{ml}$ dan dimasukkan kedalam labu leher tiga yang dilengkapi dengan pendingin bola, tabung $\mathrm{CaCL}_{2}$ anhidrat dan pengaduk magnet, kemudian ditambahkan $6,7 \mathrm{ml}(0,1 \mathrm{~mol})$ etilendiamina dan 0,54 gr $(0,01 \mathrm{~mol})$ katalis natrium metoksida dan direfluks pada suhu $70-80^{\circ} \mathrm{C}$, sambil dipantau dengan KLT menggunakan adsorben silika gel G 60 dan developer kloroform:metanol $(8: 2, \mathrm{v} / \mathrm{v})$ serta penampak noda uap iodium. Pemanasan dilanjutkan hingga reaksi sempurna selama 7-8 jam. Kemudian hasil reaksi diuapkan pelarutnya dengan rotarievaporator. Residu dimasukkan dalam corong pisah dan ditambahkan $100 \mathrm{ml}$ heksana dan dinonaktifkan katalisnya dengan menambahkan asam sitrat $10 \%$, lapisan atas ditampung dan diuapkan pelarutnya. Residu yang diperoleh dikeringkan dalam desikator dan dimurnikan melalui kolom kromatografi menggunakan absorben silika gel serta menggunakan eluent heksana:etil asetat $(8: 2, \mathrm{v} / \mathrm{v})$. Hasil yang diperoleh kemudian dianilisis dengan spektroskopi FT-IR dan dilanjutkan dengan penentuan Harga HLB dengan metode titrasi.

\section{HASIL DAN PEMBAHASAN}

Dari 500 gr biji jarak halus diperoleh minyak jarak sebanyak 248 g (49,5\%). Selanjutnya minyak jarak diesterifikasi dengan metanol menggunakan katalis $\mathrm{KOH}$ dengan pengadukan untuk memperoleh metil ester asam lemak minyak jarak campuran. Metil risinoleat yang merupakan komposisi utama dari campuran metil ester asam lemak minyak jarak campuran dapat dipisahkan dari metil asam lemak lainnya dengan menggunakan kolom kromatografi menggunakan absorben silika gel $40 \mathrm{H}$ dengan eluent petroleum eter : dietil eter $(19: 1, \mathrm{v} / \mathrm{v})$ dengan rendemen hasil reaksi sebesar $73 \%$. Untuk memantau pemisahan yang sempurna dilakukan analisis dengan KLT dengan menggunakan campuran pelarut sebagai developer dan silika gel G 60 sebagai absorbent.

Dari spektrum hasil analisis spektroskopi FT-IR (Gambar 1) menunjukkan bahwa puncak serapan pada daerah bilangan gelombang 3413,8 cm-1 yang merupakan serapan khas gugus hidroksil (disebabkan oleh regangan $-\mathrm{OH}$ ). Puncak serapan pada daerah bilangan gelombang 2927,7 dan $2854,5 \mathrm{~cm}^{-1}$ merupakan serapan khas dari vibrasi stretching $\mathrm{C}-\mathrm{H} \mathrm{sp}^{3}$ yang didukung dengan vibrasi bending $\mathrm{C}-\mathrm{H} \mathrm{sp}^{3}$ pada daerah bilangan gelombang $1458,1 \mathrm{~cm}^{-1}$. Serapan pada daerah bilangan gelombang $1739,7 \mathrm{~cm}^{-1}$ adalah frekuensi regangan gugus karbonil $(\mathrm{C}=\mathrm{O})$ dari ester yang terbentuk dan didukung dengan puncak vibrasi C-O-C ester pada daerah bilangan gelombang 1172,6 $\mathrm{cm}^{-1}$. Sedangkan spektrum 
pada daerah bilangan gelombang 1654,8 $\mathrm{cm}^{-1}$ menunjukkan gugus $\mathrm{C}=\mathrm{C}$ dari metil ester yang diperoleh (metil risinoleat). Spektrum yang menunjukkan puncak vibrasi pada daerah bilangan gelombang $725,2 \mathrm{~cm}^{-1}$ adalah vibrasi rocking $\left(\mathrm{CH}_{2}\right) \mathrm{n}$ dari asam lemak dimana $\mathrm{n} \geq 4$. Dari spektrum FT-IR metil ester yang terbentuk mengandung gugus $\mathrm{C}=\mathrm{O}$ dan $\mathrm{C}-\mathrm{O}-\mathrm{C}$ yang merupakan karakteristik dari ester dan mengandung gugus $\mathrm{OH}$ dari metil risinoleat.

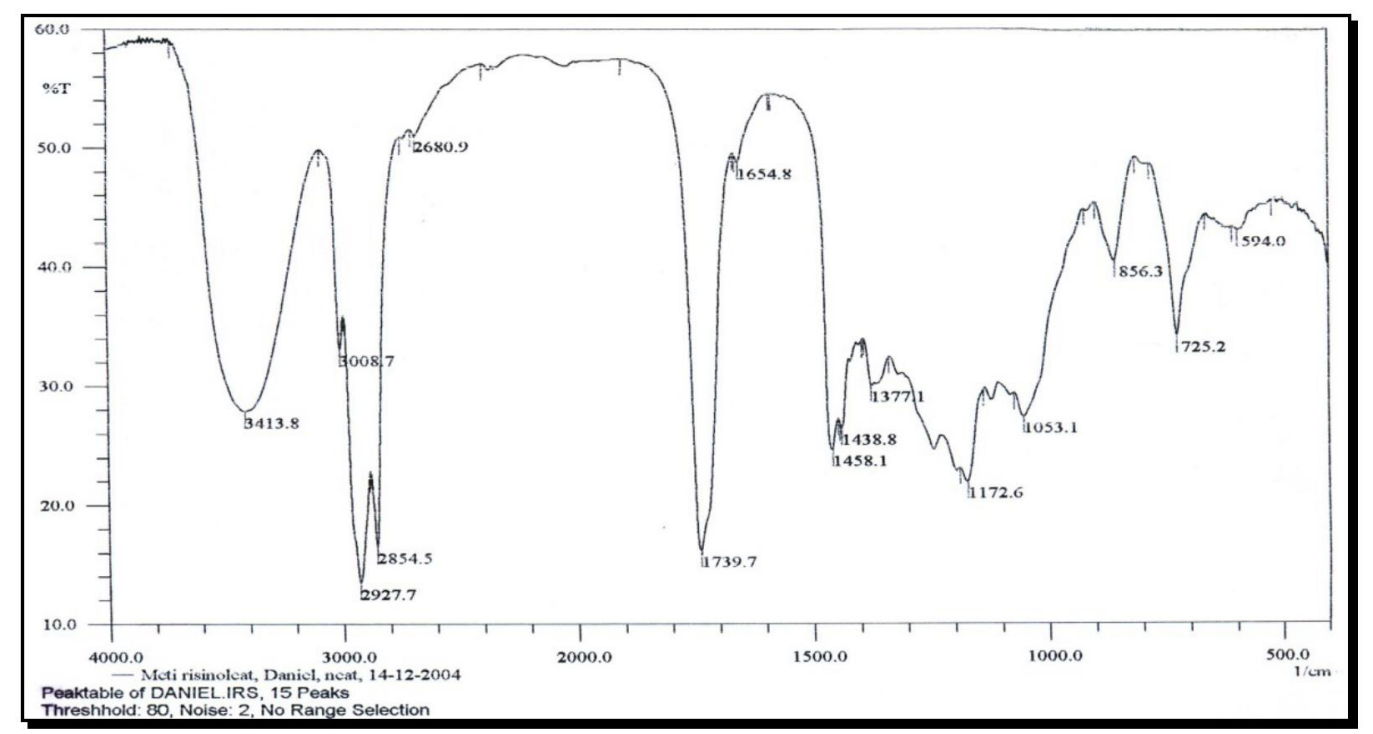

Gambar 1. Spektrum FT-IR senyawa Metil Risinoleat

Selanjutnya amidasi antara metil risinoleat dengan etilendiamina dapat menghasilkan mono amida maupun diamida berdasarkan prinsip HSAB (Hard Soft Acid Base) dimana $\mathrm{H}^{+}$dari $\mathrm{NH}_{2}$ pada etilendiamina merupakan asam keras (Hard Acid) yang mudah berikatan dengan atom $\mathrm{O}$ dari metoksi $\left(\mathrm{OCH}_{3}\right)$ yang merupakan basa keras (Hard Base) dan $\mathrm{NH}^{-}$pada gugus $\mathrm{NH}_{2}$ dari etilendiamina merupakan basa lunak (Soft Base) yang selanjutnya bereaksi membentuk ikatan dengan gugus asil, $\mathrm{R}-\mathrm{C}^{+}=\mathrm{O}$, yang merupakan asam lunak (Soft Acid). Reaksi amidasi ini dapat digambarkan sebagai berikut:
$2 \mathrm{CH}_{3}-\left(\mathrm{CH}_{2}\right)_{5}-\mathrm{CH}-\mathrm{CH}_{2}-\mathrm{CH}=\mathrm{CH}-\left(\mathrm{CH}_{2}\right)_{7}-\mathrm{CH}_{\mathrm{OH}}^{\mathrm{O}}$

Metil Risinoleat
$\mathrm{NH}_{2}-\mathrm{CH}_{2}-\mathrm{CH}_{2}-\mathrm{NH}_{2}$

Etilendiamina

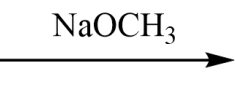

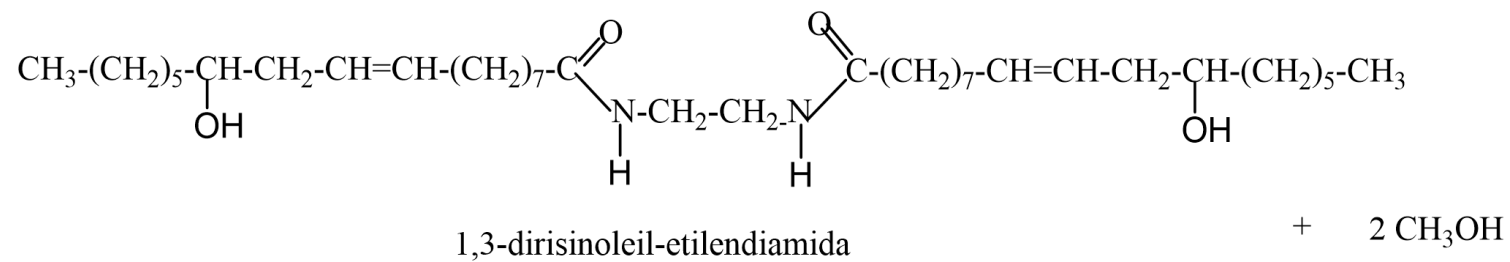

Gambar 2. Reaksi Amidasi antara metil risinoleat dengan etilendiamina

Hasil reaksi dicuci dengan n-heksana untuk menghilangkan senyawa metil risinoleat yang berlebih dan selanjutnya dicuci dengan asam sitrat $10 \%$ untuk menghilangkan katalis dan diperoleh rendemen hasil reaksi yaitu 1,3Dirisinoleil-Etilendiamida sebesar 59\%.
Dari spektrum hasil analisis spektroskopi FT-IR (Gambar 3) menunjukkan bahwa puncak serapan pada daerah bilangan gelombang 3301,9 $\mathrm{cm}^{-1}$ menunjukkan adanya gugus NH. Dan Gugus $\mathrm{OH}$ juga muncul pada daerah ini dan berimpit 
dengan gugus $\mathrm{NH}$ sehingga tidak tampak jelas pada spektrum tapi didukung dengan puncak pada aderah $1060,8 \mathrm{~cm}^{-1}$. Vibrasi $\mathrm{CH} \mathrm{sp}{ }^{2}$ muncul pada daerah bilangan gelombang 3008,7 dan $3093,6 \mathrm{~cm}^{-1}$ yang merupakan serapan khas untuk senyawa tidak jenuh. Vibrasi $\mathrm{CH} \mathrm{sp}^{3}$ muncul pada daerah bilangan gelombang 2923,9 dan $2854,5 \mathrm{~cm}^{-1}$ yang didukung dengan munculnya serapan pada daerah bilangan gelombang 1465,8 $\mathrm{cm}^{-1}$ yang menunjukkan adanya vibrasi bending $\mathrm{CH} \mathrm{sp}^{3}$. Spektrum yang menunjukkan puncak vibrasi pada daerah bilangan gelombang 721,3 $\mathrm{cm}^{-1}$ adalah vibrasi rocking $\left(\mathrm{CH}_{2}\right) \mathrm{n}$ dari asam lemak dimana $\mathrm{n} \geq 4$. Vibrasi gugus $\mathrm{C}=\mathrm{O}$ (karbonil) muncul pada daerah bilangan gelombang 1643,2 dan $1558,4 \mathrm{~cm}^{-1}$ merupakan gugs khas dari $\mathrm{C}=\mathrm{O}$ amida.

Senyawa 1,3-Dirisinoleil-Etilendiamida dianalisis harga HLBnya menggunakan metode titrasi dengan menentukan bilangan penyabunan (P) dan bilangan asam (A). Bilangan penyabunan $\mathrm{P}$ diperoleh sebesar 7,74 sedangkan bilangan asam A diperoleh sebesar 20,82. Untuk mencari nilai HLB dapat dihitung dengan menggunakan rumus $\mathrm{HLB}=20[1-(\mathrm{P} / \mathrm{A})]$. Maka diperoleh harga HLB dari senyawa 1,3-DirisinoleilEtilendiamida adalah sebesar 12,56 yang dapat digunakan sebagai bahan pengemulsi o/w.

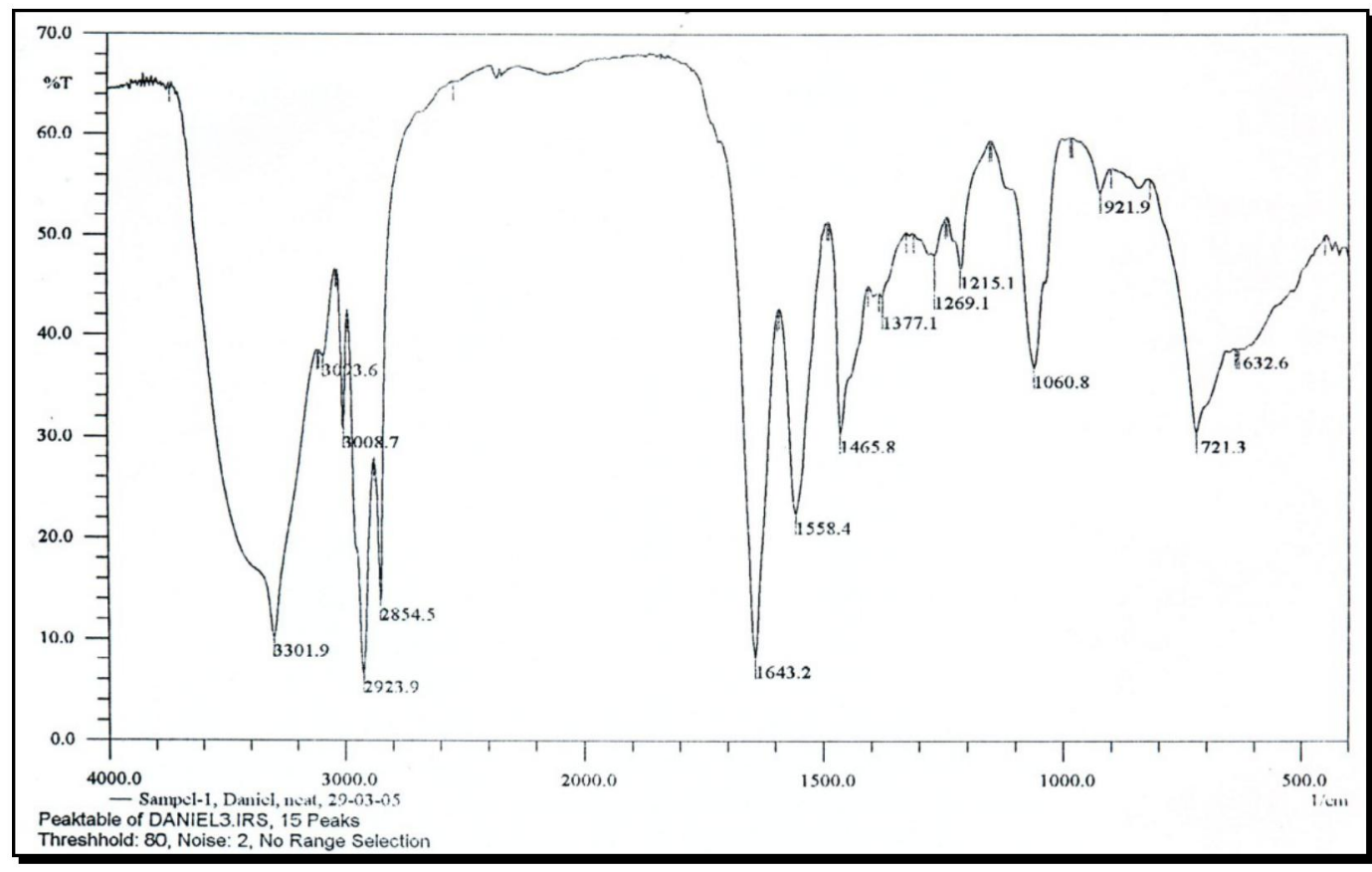

Gambar 3. Spektrum FT-IR Senyawa 1,3-Dirisinoleil-Etilendiamida

\section{KESIMPULAN}

1. Senyawa 1,3-Dirisinoleil-Etilendiamida dapat dihasilkan melalui reaksi amidasi metil risinoleat dengan etilendiamina dengan perbandingan 2:1 dengan rendemen sebesar $59 \%$

2. Senyawa 1,3-Dirisinoleil-Etilendiamida yang diperoleh memiliki harga HLB sebesar 12,56 dan dapat digunakan sebagai bahan pengemulsi o/w.

\section{SARAN}

Perlu dilakukan penelitian lanjutan tentang penggunaan senyawa metil risinoleat dan senyawa 1,3-Dirisinoleil-Etilendiamida dalam bidang kosmetik, obat-obatan dan bidang farmasi lainnya dalam pengembangan bidang kimia oleo.

\section{DAFTAR PUSTAKA}

[1] Miller, A. J., and F. E. Newel, (2014) "Modern Experimental Organic Chemistry", Western Washington University.

[2] Harapan, P., (2016), “ Sintesis 12-(Asetoksi) Metil Okta Deka-9-Ene-1-oat dari Minyak jarak (Ricinus communis L.) melalui reaksi interesterifikasi dan klorinasi yang diikuti asetilasi", Skripsi Jurusan Kimia FMIPA USU, Medan

[3] Frykman, H. B., Isbell, T. Cermark, S. C. (2012), "5-Hydroxy Fatty Acid Amides From $\delta$-Laktone and Alkyl Glukosamines", $\underline{\text { J }}$ Surf. And Detergent., 3, 179.

[4] Mittlebach, M. dan P. Trithard, (1998), “Diesel Fuel Derived From Vegetable Oils, 
III, Emission Test, Using Methyl Esther of Used Frying Oil", ‥ Am. Oil. hem. Soc., 65, 1185.

[5] Borch, C., Jansen, J. Benny, M. Kim, and M. Jorgen, (1997), “Analysis of Seed Oil from Ricinus communis and Dimorphoteca pluvialysis by Gas Supercritical Fluid

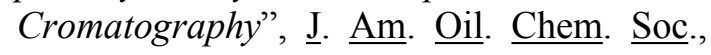
74 (3), 227-284

[6] Brahmana, H. R., (1991), " Amida Asam Lemak Sebagai Bahan Pemantap Lateks", Laporan Penelitian, 4, LP-USU.

[7] Haustin, J. H., (1997), “ Detergent Changing Expectation, Contents", Inform, (8), 928.

[8] Maag, (1984), "Fatty Acid Perivati Ves: Important Surfactant For House Hold,
Cosmetic and Industrial Purpose”, ‥ Am. Oil. Chem. Soc., 61.

[9] Peter, S. Piispanen, Marcus Persson, and Torbjoorn Norin, (2004), Surface Properties of Surfactant Derivated from Natural Product. Part I: Synthesis and Structure Property Relationships-Solubility and Emulsification ",J. Surf. And Detergent., 7 (2), 147-160.

[10] Rumamurthy, S., Monahar, V. And Mani, V. V. S., (1998), "Characterization of Fatty Acid Isomers in Dehydrated Castor Oil and GC-MS Tecnique", JAOCS. Vol. 75, 127.

[11] Vogel, S., (1998), “ A Text Book of Practical Organic Chemistry Including Qualitative Organic Analysis", London. 